DOI 10.37882/2223-2982.2021.06-2.20

\title{
УЧЕБНО-МЕТОДИЧЕСКИЕ КОМПЛЕКТЫ И ПОСОБИЯ ПО АНГЛИЙСКОМУ ЯЗЫКУ ДЛЯ ОБУЧЕНИЯ ДОШКОЛЬНИКОВ И УЧАЩИХСЯ ПЕРВОГО КЛАССА: АНАЛИТИЧЕСКИЙ ОБЗОР
}

\section{EDUCATIONAL AND METHODOLOGICAL KITS IN TEACHING ENGLISH TO CHILDREN OF PRESCHOOL AND PRIMARY SCHOOL AGE: AN ANALYTICAL REVIEW}

\section{E. Mayakova}

Summary: The article will focus on Russian educational and methodological kits and foreign manuals for teaching English for preschoolers and primary schoolchildren. The analytical review presented in the article will help the teacher, the teacher of additional education to determine the variety of materials for training and choose the optimal product. The author makes a special emphasis on Russian teaching materials for mastering English at an early stage of education.

Keywords: teaching materials, manuals, English, preschoolers, primary schoolchildren, teaching.

\author{
Маякова Елизавета Владимировна \\ К.п.н., дочент, ГАОУ ВО Московский городской \\ педагогический университет \\ L_mayakova@mail.ru
}

Аннотация: В статье представлен анализ отечественных учебно-методических комплектов и зарубежных пособий для обучения дошкольников и учащихся первого класса английскому языку. Аналитический обзор поможет учителю, педагогу дополнительного образования определиться в многообразии материалов для обучения и выбрать оптимальный продукт. Особый акцент в статье автор делает на отечественные учебно-методические комплекты при овладении английским языком в условиях раннего иноязычного образования.

Ключевые слова: УМК, пособия, английский язык, дошкольники, учащиеся первых классов, обучение, овладение.
A ктуальность овладения английским языком детьми пяти-шестилетнего возраста обусловлена требованиями общества и развивающим потенциалом иностранного языка, что обосновано теоретически и доказано экспериментально (Гальскова Н.Д., Никитенко 3.Н.) [4, с. 3]. С 1987 по 1994 гг. в Российской Федерации проводился широкомасштабный эксперимент по раннему обучению иностранным языкам в дошкольных учреждениях, результатами которого явилось создание принципиально новых пособий для дошкольников и учащихся первого класса, открытие новых специальностей (учитель начальных классов с правом преподавания иностранного языка, воспитатель с правом преподавания английского языка) и появление новых факультетов и кафедр.

В настоящие время иностранный язык включен (по желанию и просьбам родителей) во многие дошкольные образовательные учреждения, а также в первый класс начальной школы. Изданы не только отечественные, но и зарубежные пособия, однако развивающий потенциал последних зачастую сомнителен.

Задача данной статьи заключается в том, чтобы помочь учителю сориентироваться в разнообразии подходов и методических пособий по английскому языку для дошкольников и учащихся первого класса в целях успешной реализации приоритетов дошкольной и начальной ступеней обучения.

В качестве доминантного критерия анализа учебных пособий выступает их ориентированность на:

1. развивающие цели, зафиксированные в стандарте дошкольного образования;

2. цели и результаты дошкольного иноязычного образования.

ФГОС ДО утверждает, что «специфика дошкольного детства (гибкость, пластичность развития ребенка, высокий разброс вариантов его развития, его непосредственность и непроизвольность), а также системные особенности дошкольного образования (необязательность уровня дошкольного образования в Российской Федерации, отсутствие возможности вменения ребенку кой-либо ответственности за результат) делают неправомерными требования от ребенка дошкольного возраста конкретных образовательных достижений и обусловливают необходимость определения результатов освоения образовательной программы в виде целевых ориентиров» [13, с. 25-26].

Социальное значение дошкольной ступени заключается в создании условий для формирования психологической готовности ребенка к обучению в школе. 
Стратегической целью дошкольного иноязычного образования является личностное развитие ребенка и формирование его культуры (речевой, коммуникативной, нравственной) средствами иностранного языка. Таким образом, целевыми приоритетами дошкольного иноязычного образования являются когнитивное, речевое, коммуникативное и нравственное развитие личности ребенка [9, с. 26].

Для анализа выбраны пособия, которые используют педагоги, обучающие детей английскому языку в дошкольном учреждении и в первом классе начальной школы, а именно: отечественные учебно-методические комплекты (УМК) («Английский язык. Первые шаги», «l love English») и зарубежные методические пособия («Happy House (New Edition) 1», учебный курс «Letterland Fix-it Phonics», «Hooray! Let's play!», «Potato Pals», «Get Ready 1, 2»).

Обратимся к отечественным учебно-методическим комплектам и начнем наше рассмотрение с УМК «Английский язык. Первые шаги», предназначенный для дошкольников пяти-шести лет и школьников первого класса $[10,11,12]$. Это единственный УМК, который прошел проверку в широкомасштабном российском эксперименте, и эффективность которого доказана многолетним опытом работы учителей, использующих этот комплекс в своей практике.

Проведенный анализ позволяет утверждать, что данный УМК реализует деятельностный подход [6, с. 160], принцип развивающего иноязычного образования и реализует рассмотренную выше цель иноязычного образования в дошкольном учреждении и первом классе.

УМК основан на уникальной развивающей технологии, направленной на формирование у детей интереса к новому языку и развитие у них самостоятельной иноязычной речи. Данная технология исключает механическое заучивание и хоровое проговаривание и обеспечивает взаимосвязанное коммуникативное, когнитивное и нравственное развитие детей.

Еще одно достоинство этого пособия мы усматриваем в том, что данный УМК целенаправленно развивает у детей фонологическую способность (способность к звуковому осознанию иноязычной речи), сформированность которой обеспечивает успешность обучения чтению и письму на английском языке во втором классе.

Овладение детьми английским языком включено в контекст сказки Ф. Баума «Волшебник страны Оз». Дети погружаются в мир иной культуры и нового языка, взаимодействуют с персонажами данного произведения и используют язык как реальное средство общения.
Этому способствуют:

- обучение языку в виде диалогического общения, что отвечает их возрастным возможностям и позволяет создавать естественную мотивацию речи детей;

- использование игровых речемыслительных задач как способа творческого овладения языком;

- формулирование речемыслительных задач на родном языке, так как на иностранном языке невозможно заинтересовать детей, поскольку они не поймут, о чем пойдет речь: приведем пример такой речемыслительной задачи, «Чтобы расколдовать наших зверей (это мотив для ребенка, это то, ради чего он будет говорить), нужно рассказать какого они цвета» (это цель речевого действия);

- ознакомление с грамматическим явлением на основе занимательной проблемной истории, когда дети с помощью учителя открывают секреты английского языка и понимают, что речь - это не нагромождение слов, что речь строится по правилам;

- развитие представлений об иной культуре с опорой на свой опыт овладения родной культурой: «как у нас и как у них», «что одинаково, что различно».

Следует отметить, что овладение чтением и письмом на английском языке в детском саду и первом классе не предусматривается. Мы солидарны в этом с авторами, поскольку обучение дошкольников и первоклассников грамоте чужого языка признаётся психологами [6, с. 160] и психофизиологами [1] неполезным и даже вредным, поскольку при этом задействуются те структуры их мозга, которые еще не готовы к такой деятельности.

Проведенный анализ также позволяет утверждать, что данный УМК обеспечивает преемственность дошкольного образования и начальной школы за счёт развития эмоционально-волевой сферы личности ребёнка и его когнитивных (познавательных) способностей, составляющих основу способности к иноязычной речевой деятельности.

Следует добавить также, что пособие носит интерактивный характер, каждое задание для детей в учебнике снабжено QR-кодом: все страницы озвучены детьми-носителями языка.

Обратимся далее к рассмотрению учебно-методического комплекта «l love English», разработанный для детей от двух до девяти лет [8]. Автор создал многоступенчатый курс, однако в статье приводится анализ нулевой и первой ступени, которые предназначены для обучения детей дошкольного возраста и первоклассников.

Проведенный анализ свидетельствует о том, что об- 
учение английскому языку дошкольников и учащихся первого класса по предлагаемой методике строится на погружении в языковую среду, многократном прослушивании, комфортном взаимодействии с учителем и сверстниками, использовании беспереводной семантизации, активизации подвижной и речевой деятельности, на использовании песен, диалогов, записанными носителями языка, что создает аутентичность восприятия речи. Многократное прослушивание разговорных записей дома и обучение на занятиях, по мнению автора, способствует тому, что постепенно от занятия к занятию язык становится частью жизни детей и что у них появляется возможность научиться свободно говорить на английском языке. Ступени «l can sing» и «l can speak» подготавливают ребенка к овладению чтением и письмом во втором классе школы.

В основе предлагаемой методики лежит механизм импринтинга, который, как утверждает автор, является путем создания образа языка у ребенка через многократное прослушивание отрабатываемых структур на основе аудиокомплекса.

Анализ принципов, положенных в основу УМК позволяет нам выделить как самый основной, принцип минимакса, позволяющий задействовать родителей в процессе обучения. Родителям отводится особая роль в поддержании интереса к обучению английскому языку, они могут выбирать формат взаимодействия с ребенком в овладении языком. «Минимум» обозначает дать то, что заложено программой. «Максимум» подразумевает любые уместные дополнения как в материалах и заданиях, так и в разговорной речи учителя.

При таком подходе родители выбирают стратегии в обучении детей английскому языку. Так, по программе «Минимум» необходимо обеспечить техническую сторону процесса, напоминать ребёнку прослушать аудиоурок и выполнить задание, помочь оформить книжку-самоделку, посещать родительские собрания и открытые занятия. Программа «Максимум» определяется возможностями родителей в знании языка и включает в себя игру в учителя и ученика, когда ребенок выступает в роли учителя до общения на английском в бытовых условиях и игры в английские игры.

Положительным, как нам представляется, в данном пособии является активизация у детей основных каналов восприятия: визуального, аудиального, кинестетического. Поскольку на занятиях детям необходимо видеть предметы, слышать название, двигаться, брать игрушки для запоминания.

Проведенный анализ, свидетельствует о том, что авторские УМК «Английский язык. Первые шаги» и «l love English» отвечают целям дошкольного образования и за- явленным в начале статьи критериям в целом, поскольку в них прослеживается ориентация на личностное развитие дошкольников и первоклассников, развитие их когнитивных способностей, обеспечивается естественный путь овладения иностранным языком.

Занятия, проводимые в рамках предложенных в пособиях тем, могут удовлетворить естественное любопытство и любознательность детей дошкольного возраста, дополнить уже имеющиеся у них знания на родном языке, расширить их кругозор [7, с. 87].

Вместе с тем в УМК «l love English» предлагаются задания, которые задействуют механическую память детей, поскольку им приходиться многократно повторять слова и речевые образцы, что согласно исследованиям психофизиолога [2] приводит к левополушарному утомлению.

Далее перейдем к рассмотрению зарубежных пособий по английскому языку для дошкольников и учеников первого класса, которые на основе проведенного анализа, систематизированы нами в две группы. В первую группу включены пособия, которые можно использовать как дополнительные пособия, например, для создания аутентичной языковой среды, во вторую группу - пособия, которые нельзя использовать в детском учреждении, поскольку реализованная в них технология наносит вред психическому развитию детей и не обеспечивают становление самостоятельной речи на английском языке.

Обратимся к пособиям первой группы (УМК «Нарру House (New Edition) 1», «Potato Pals», «Hooray! Let's play!»), которые во многом уступают отечественным пособиям, поскольку построены на имитативной технологии, предполагающей механическое повторение и заучивание.

Проведенный анализ, показал, что данные пособия объединяет то, что дети:

1. овладевают языком через устные виды речевой деятельности - говорение и аудирование;

2. разучивают англоязычные песни и выполняют упражнения на соотнесение, раскрашивание и дорисовывание различных предметов по темам пособия;

3. прослушивают большое количество разнообразных аутентичных аудиофрагментов, которые они, к сожалению, не всегда понимают.

Между анализируемыми пособиями существуют и принципиальные различия, которые заключаются как в тематике, так и наполняемости пособий раздаточным материалом и постерами.

Так, в УМК «Happy House (New Edition) 1» для детей пя- 
ти-шести (семи) лет [17] представлено много ярких и коротких историй, которые дети могут разыгрывать в виде сценок, используя мягкие игрушки, одеваемые на руки. Авторы отдельно выделяют социокультурный материал, рассказывающий о традициях празднования рождества и пасхи, проживания в отдельном доме (detached house).

Пособие «Potato Pals» предназначенное для детей пяти-семи лет [16], содержит забавные истории, состоящие из простых предложений, пополняющих базовый словарный запас и шаблоны с системой подсказок. Темы, предложенные в пособии для овладения английским языком детьми дошкольного возраста актуальны, так как отражают действия детей дома - мир предметов, с друзьями - мир социальных отношений, с окружающим миром - мир природы [5, с. 43].

Проведенный анализ пособия «Hooray! Let's play!» для детей от трех до пяти лет [18] показал, что, обучение языку также, как во всех зарубежных УМК, построено на имитации: проговаривании под музыку, двигательной активности и повторении слова за воспитателем. Вызывает сомнение и правомерность обучение иностранному языку детей, начиная с трехлетнего возраста в искусственных условиях и вне среды, где говорят на этом языке. В исследованиях выдающегося отечественного психолога А.А. Леонтьева доказано, что дети готовы к осознанному овладению иностранным языком с 5 лет [6, c. 161].

Обратимся далее к анализу второй группы зарубежных пособий «Letterland Fix-it Phonics», «Get Ready 1, 2», которые, и это следует констатировать, не отвечают требованиям стандарта дошкольного образования и не реализуют цели иноязычного дошкольного образования. Кроме того, реализованная в них технология разработана для обучения детей английскому языку как родному языку, а не иностранному.

В отечественной практике обучения детей иностранным языком, к сожалению, находит применение учебный курс «Letterland Fix-it Phonics», [19], широко рекламируемый в нашей стране. Важно отметить, что этот курс рассчитан на детей, которые овладевают английским языком как родным и которые значительно отстают в психическом развитии от своих сверстников.

Данный УМК предполагает обучение дошкольников чтению на чужом языке. Детям становится трудно запоминать буквы, потому что они еще не умеют читать на родном языке и у них не сформированы те когнитивные функции, которые позволили бы им с такими трудностями справиться.

Авторы безосновательно утверждают, что их адаптированный курс может быть использован для обучения английскому языку как иностранному в разных странах, т.е. детям предлагается один «абстрактный» курс. Тем самым авторы завуалированно указывают, что в методике Letterland отсутствует культуроведческий компонент.

Детям предлагается то, что превышает их психофизиологические возможности: читать и писать на иностранном языке, еще до того, как они научились это делать на родном. Тем самым у них перегружается зрительный анализатор, система зрительного восприятия в целом и тем самым форсируется психическое развитие, в том числе за счет перегрузки левого (логического) полушария.

Работа по данному УМК изначально предполагает владение детьми устной речью, минимальным словарным запасом, который может быть накоплен к такому раннему возрасту только у носителей языка. Все вышесказанное свидетельствует о том, что учебное пособие Letterland не является здоровье сберегающим и не подходит для овладения детьми английским языком в дошкольных учреждениях Российской Федерации.

Основное содержание курса «Get Ready 1, 2» для детей пяти-семи лет $[14,15]$ составляет изучение аутентичных считалочек и песенок на основе постеров, что, по мнению авторов должно способствовать взаимодействию детей между собой в подвижной игре.

Между тем данный курс, к сожалению, также включает обучение грамоте английского языка (дети изучают буквы и пишут их в специальных тетрадях), что недопустимо в дошкольном возрасте для детей, изучающих английский язык как иностранный. Такой подход характерен для носителей языка и, соответственно, курс в полном объеме может применяться только в англоговорящих странах, т.к. русскоязычным детям в дошкольном возрасте необходимо усвоить родную систему языка. Согласно исследованиям известного отечественного психофизиолога М.М. Безруких, обучение письму и чтению - это чрезвычайно сложный и длительный процесс. И для того, чтобы этот процесс был эффективным, необходимо, чтобы созрели механизмы зрительной дифференцировки. Эти механизмы созревают у большей части детей не раньше, чем к пяти-шести годам. До тех пор, пока у него не сформировался родной язык и родная речь, давать второй язык нецелесообразно [3, с. 7].

Несмотря на то, что все проанализированные зарубежные пособия (и первой и второй группы) отличаются красочностью картинок (карточек, постеров), реализованная в них технология базируется на устаревшей имитативной теории овладения языком, не ориентирована на реализацию целей отечественного дошкольного образования и не направлена на развитие личности дошкольника как субъекта своей культуры. 
В заключение отметим, что выбор того или иного пособия педагогом - это очень ответственное дело и требует вдумчивого профессионального подхода. Проведенный анализ подтвердил наше мнение о том, что приоритетными выступают отечественные УМК, кото- рые отвечают современным тенденциям развития методической мысли в нашей стране: развития личности дошкольника и первоклассника, активизации его мышления, становления эмоционально-волевой сферы и формирование способности к иноязычному общению.

\section{ЛИТЕРАТУРА}

1. Безруких М.М. Развитие мозга и формирование познавательной деятельности ребенка. - Воронеж: НП0 «Модек», 2009. - 432 с.

2. Безруких М.М. Трудности обучения в начальной школе. Причины, диагностика, комплексная помощь. - М.: Эксмо, 2009.

3. Берлова Е. Про маленькую Сашу и всех других детей. Книга для довольных родителей. Цифровая книга, 2015.

4. Гальскова Н.Д., Никитенко 3.Н. Иностранный язык в дошкольном образовании: ценностные приоритеты. // Иностранные языки в школе. - 2019. № 3. - C. 2-9.

5. Горлова Н.А., Маякова Е.В. Деятельностная стратегия обучения английскому языку детей дошкольного возраста: Учебно-методическое пособие для студентов. - М.: МГПУ, 2009. - 120 с.

6. Леонтьев А.А. Естественность иноязычного общения как основополагающий принцип обучения языку. // Психолингвистика и межкультурные взаимопонимание: тезисы докладов 10 Всесоюзного симпозиума по психологии и теории коммуникации. - М., 1991. - С. 159-164.

7. Маякова Е.В. Содержание обучения английскому языку детей дошкольного возраста. // Вестник Московского городского педагогического университета. Серия «Филология. Теория языка. Языковое образование». -2012. - № 1(9). - С. 85-90.

8. Мещерякова В.Н. Методика обучения детей I love English [Электронный ресурс]. URL: https://www.i-love-english.ru/ (дата 0бращения: 08.10.2020).

9. Никитенко 3.Н., Никитенко Е.А. Цели и результаты овладения иностранным языком. // Дошкольное воспитание. - 2017. - № 5. - С. 26-30.

10. Никитенко 3.Н., Никитенко Е.А. Английский язык. Первые шаги: Учебное пособие для детей 5-6 лет и учащихся 1 класса. - М.: БИНОМ, 2020. - 112 с.

11. Никитенко 3.Н. Английский язык. Первые шаги: Рабочая тетрадь к учебному пособию для детей 5-6 лет. В двух книгах. - М.: Бином, 2019. - 96 с.

12. Никитенко 3.Н. Английский язык. Первые шаги: Книга для педагога к учебному пособию для детей 5-6 лет. - М.: БИНОМ, 202. - 284 с.

13. Федеральный государственный образовательный стандарт дошкольного образования [Электронный ресурc]. URL: https://fgos.ru/ (дата обращения: 08.10.2020).

14. Hopkins F. Get Ready 1, 2. - Oxford University Press, 1997.

15. Hopkins F. Get Ready. Teacher'sbook 1, 2. - Oxford University Press, 1997.

16. Jackson P., Kimura R. Potato pals 1, 2. - Oxford University Press, 2004.

17. Maidment S., Roberts L. Happy House (New Edition). - Oxford University Press, 2009.

18. Puchta H., Gerngross G. Hooray! Let's Play! - British English version, 2012.

19. Wendon L., Holt L. Letterland. Fix-it Phonics. - Letterland International, 2007.

() Маякова Елизавета Владимировна (L_mayakova@mail.ru). 